\title{
Sulfur cycling at the surface water- groundwater interface in riparian wetlands
}

\author{
Crystal NG ${ }^{1}$, CARa SANTElli ${ }^{2}$, CARla Rosenfeld ${ }^{3}$, \\ AUBREY DUNSHEE ${ }^{4}$, DAN KAPLAN ${ }^{5}$, KENNETH M \\ KEMNER $^{6}$,JOSH TORGESON ${ }^{7}$, SHREYA SRIVASTAVA $^{8}$, \\ AMANDA YOURD ${ }^{9}$ \\ ${ }^{1}$ University of Minnesota-Twin Cities, gcng@umn.edu \\ ${ }^{2}$ University of Minnesota-Twin Cities, santelli@umn.edu \\ ${ }^{3}$ Northwestern University, carla.rosenfeld@ northwestern.edu \\ ${ }^{4}$ University of Minnesota-Twin Cities, duns0034@umn.edu \\ ${ }^{5}$ Savannah River National Laboratory, \\ daniel.kaplan@srnl.doe.gov \\ ${ }^{6}$ Argonne National Laboratory, Kemner@anl.gov \\ ${ }^{7}$ University of Minnesota-Twin Cities, torge158@umn.edu \\ ${ }^{8}$ University of Minnesota-Twin Cities, sriva215@umn.edu \\ ${ }^{9}$ University of Minnesota-Twin Cities, University of Minnesota- \\ Twin Cities, aryourd@umn.edu
}

Riparian wetland hyporheic zones, where oxic surface water and anoxic groundwater mix, undergo spatiotemporally dynamic conditions that drive steep geochemical redox gradients and promote diverse and fluctuating microbial activity. Iron $(\mathrm{Fe})$ and sulfur (S) are often abundant in organic-rich wetlands, yet the role of $\mathrm{S}$ in wetland biogeochemical cycling - especially in hydrologically dynamic conditions - is poorly resolved. Our aim is to clarify the roles of $\mathrm{S}$ and $\mathrm{Fe}$ in redox reactions coupled to carbon (C) oxidation at dynamic surface water-groundwater interfaces in wetlands. A better understanding is needed in order to predict how wetland ecosystems drive global $\mathrm{C}$ cycles and greenhouse gas emissions, and how they promote water quality by transforming nutrients and sequestering metals. We will present results from three riparian wetlands that span high to relatively low sulfate concentrations, including two mining-impacted sites in Minnesota as well as the Argonne Wetland Hydrobiogeochemistry SFA site in South Carolina, Tims Branch. Analyses include a combination of geochemical field measurements, spectroscopic speciation, hydrological monitoring, and microbial analysis to interrogate abiotic and biotic processes. Different observations are being integrated through reactive transport modeling. We are finding evidence for both "cryptic" $\mathrm{S}$ cycling and anaerobic methane oxidation, with spatiotemporal distributions controlled by surface water-groundwater exchanges. Our results indicate that $\mathrm{S}$ may play an important role in biogeochemical cycling across a gradient of concentrations, depending on hydrologic conditions, and this should be taken into consideration when evaluating the environmental function of wetlands. 
